\title{
Vouchers: A Legitimate Tool for Immediate Improvement in Student Academic Achievement in Urban Schools?
}

Matthew A. Fansler
Cedarville University

Cedarville University

Follow this and additional works at: http://digitalcommons.cedarville.edu/education_theses

Part of the Education Commons

\section{Recommended Citation}

Fansler, Matthew A., "Vouchers: A Legitimate Tool for Immediate Improvement in Student Academic Achievement in Urban Schools?" (2008). Master of Education Research Theses. 46.

http://digitalcommons.cedarville.edu/education_theses/46 


\title{
VOUCHERS:
}

\section{A LEGITIMATE TOOL FOR IMMEDIATE IMPROVEMENT IN STUDENT ACADEMIC ACHIEVEMENT IN URBAN SCHOOL DISTRICTS?}

\author{
A thesis submitted in partial fulfillment \\ of the requirements for the degree of \\ Masters of Education
}

\section{By}

MATTHEW AARON FANSLER

B.Ed., University of Toledo, 1997

2008

Cedarville University 
CEDARVILLE UNIVERSITY

SCHOOL OF GRADUATE STUDIES

May 3, 2008

I HEREBY RECOMMEND THAT THE THESIS PREPARED UNDER MY SUPERVISION BY Matthew Aaron Fansler ENTITLED Vouchers: A Legitimate Tool for Immediate Improvement in Student Academic Achievement in Urban School Districts? BE ACCEPTED IN PARTIAL FULFILLMENT OF THE REQUIREMENTS FOR THE DEGREE OF Master of Education.

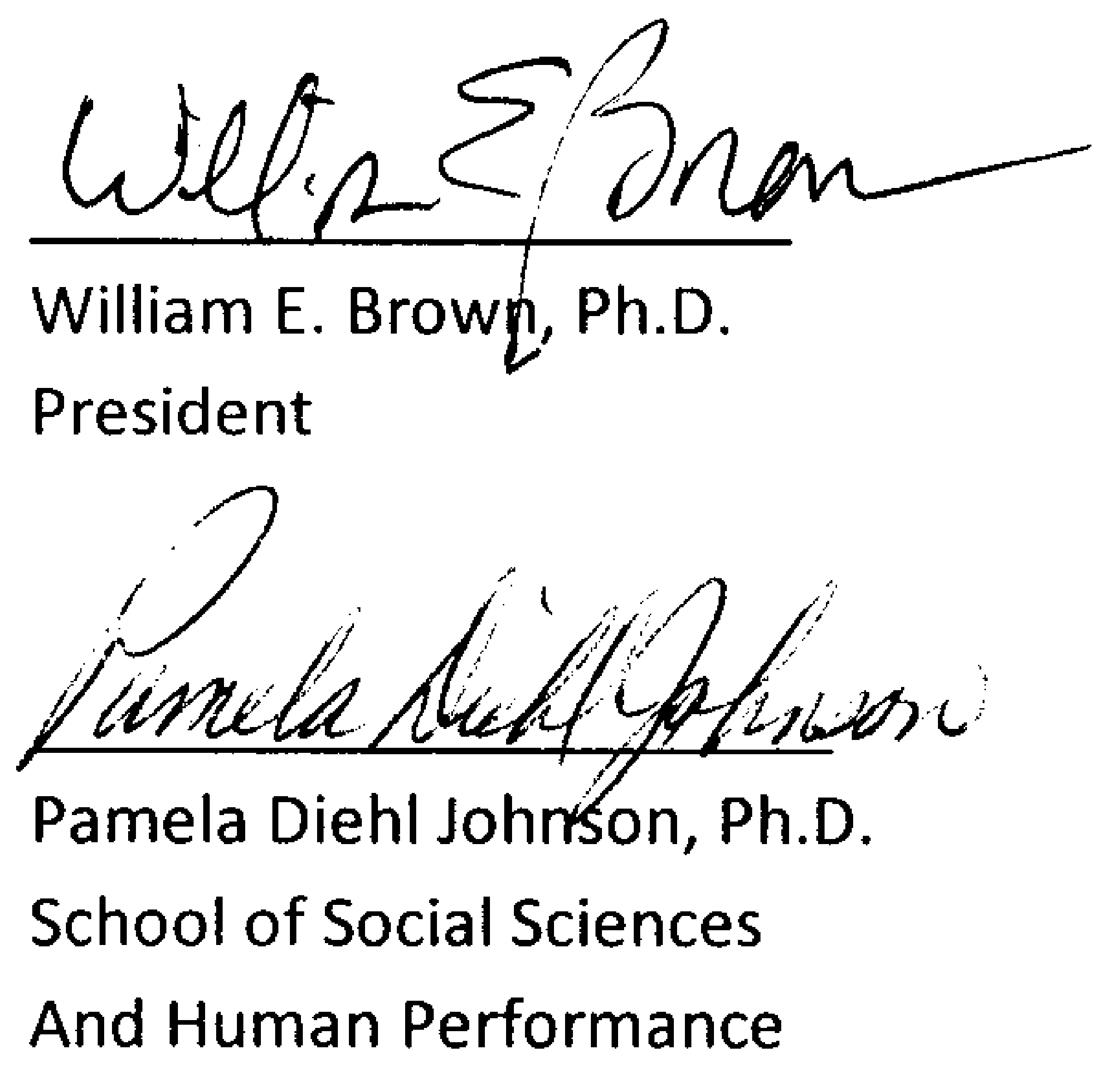

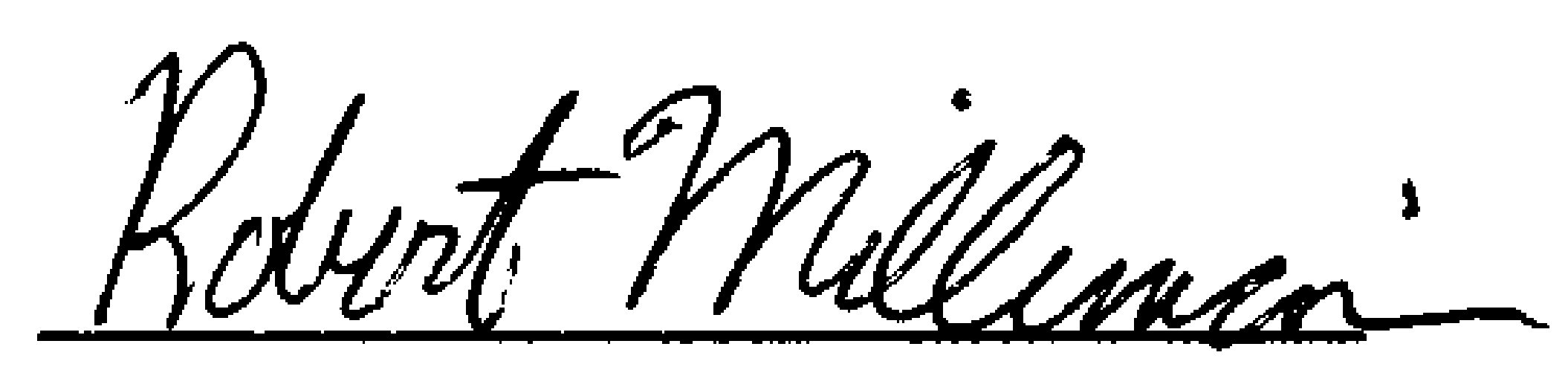

Robert W. Milliman, Ph.D.

Academic Vice President

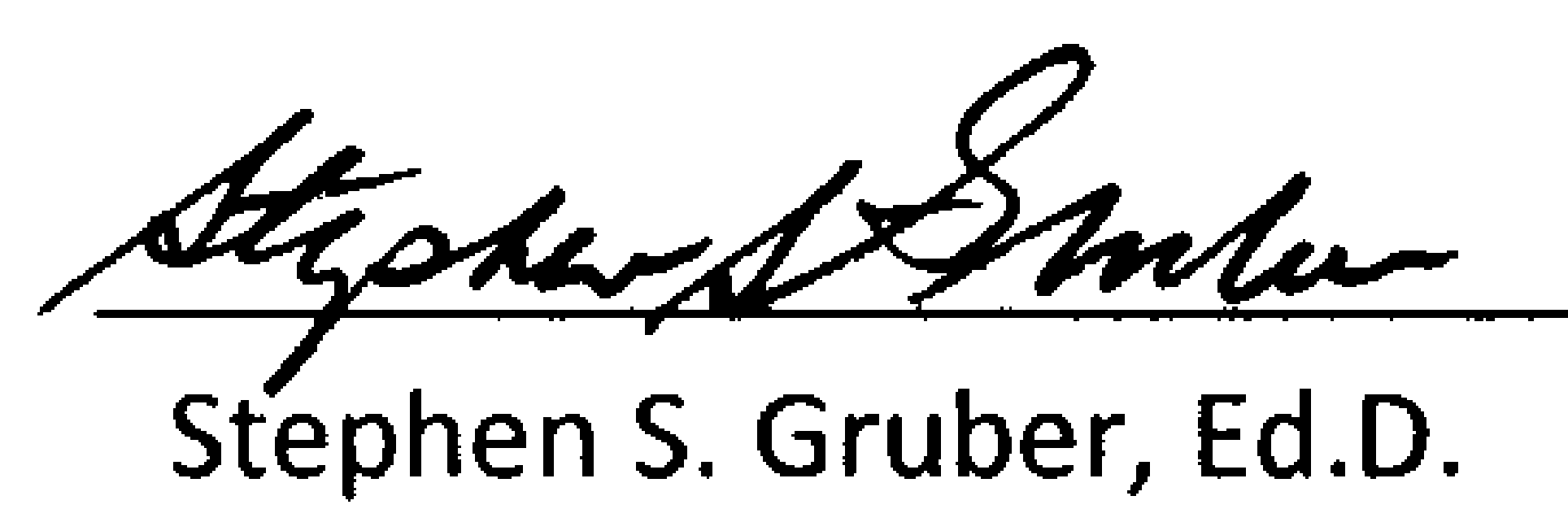

Education Department Chair Thesis Advisor 


\begin{abstract}
Fansler, Matthew A. M.Ed., Education Department, Cedarville University, 2008. Vouchers: A Legitimate Tool for Immediate Improvement in Student Academic Achievement in Urban School Districts?

Based on the growing debate surrounding vouchers, and the varying positions on the effect they may or may not have on student performance, this paper hopes to establish what immediate effects the use of a voucher system has on the academic performance of high school students in an urban setting. Does the use of a voucher offer a legitimate solution to raising student performance or does the voucher simply serve as a means of moving students from one school to another? In order to determine the legitimacy of a current voucher program, data will be collected that is directly linked to student academic performance. The importance of this study is to determine the validity and efficacy of voucher programs currently in place.
\end{abstract}




\section{TABLE OF CONTENTS}

I. INTRODUCTION AND PURPOSE ........................................

Application to Current School...........................................

Biblical Integration.................................................

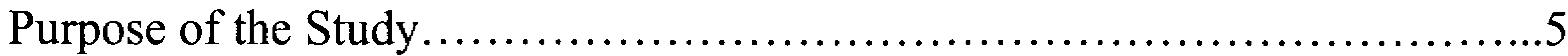

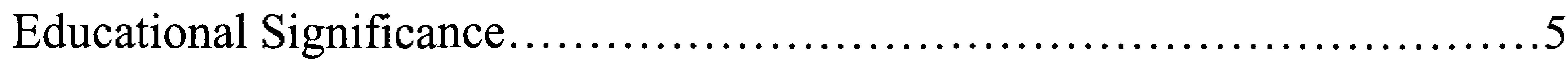

Method of Study .......................................................

Brief Literature Review..................................................

The Test Results......................................................... 10

Definitions..............................................................

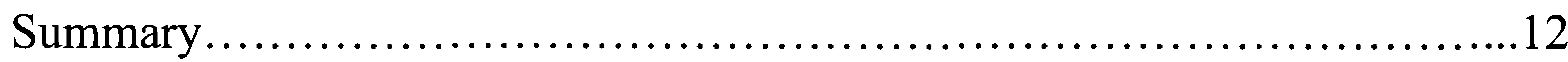

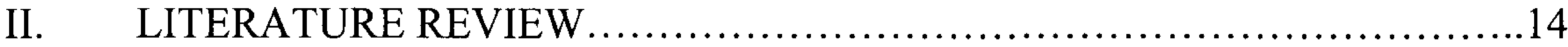

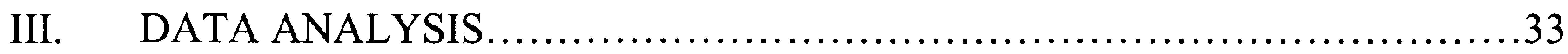

Core Knowledge Tests....................................................34

Scaled Score Ranges................................................

Mean Scaled Score Ranges for High School 1............................36

Voucher Student Scaled Scores..........................................37

IV. CONCLUSIONS AND EXPLANANTIONS....................................39

Recommendations...................................................44

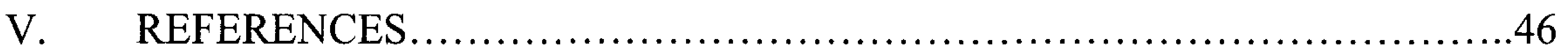




\section{LIST OF FIGURES}

Figure

Page

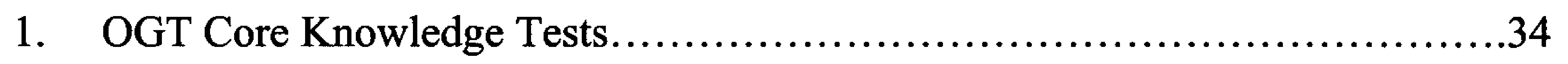




\section{LIST OF TABLES}

Figure Page

1. Score ranges and performance levels for all subjects. .35

2. Mean scaled scores and standard deviations for high school 1 core subjects...36

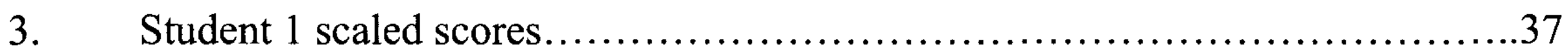

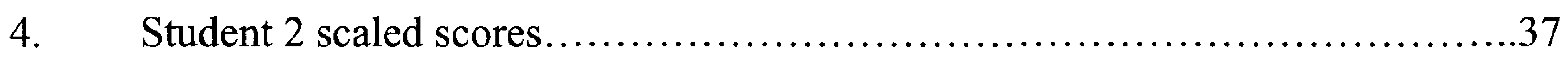




\section{INTRODUCTION}

As more school districts both urban and rural face an overwhelming onslaught of dwindling state finances and declining student enrollment, the role of alternative schooling and publicly funded voucher programs continues to stir public debate. The idea that the problems of inequity faced in urban and rural schools can be solved by a system that offers free or partially subsidized tuition to the school of choice is for many people a radical idea. To a majority of people who have always viewed the public school system as a bastion of democratic idealism, this notion that a system based on selective segregation can achieve positive results runs contrary to their own notion of what public schooling should reflect. Still, the voucher option is becoming more widespread each year.

Recently the State of Ohio voted to not only continue their support of a voucher program currently ongoing in the city of Cleveland, but they also broadened the program to include more schools and more state funding. It would seem that with voucher programs gaining more acceptance and widespread use, it is inevitable that they will continue to become an integral part of our modern education system. In light of such recent attempts as in the State of Ohio to expand and modify the scope of voucher programs in public school districts, it is only fitting that a fair analysis of the different views in favor of and in opposition to such voucher programs be taken into consideration. What was once something that many people were only vaguely aware of has now become 
a flash point in the debate and battle over the possible future of public schooling as we have come to know it.

The heart of the voucher debate stems from the very idea of what a voucher is and how it should be utilized. The first person to actually suggest the use of such system was the well known economist Milton Friedman, whose idea of vouchers when presented in the early 1960 's was one based on the view that public schools were essentially a government run monopoly with very little incentive to produce a high quality education. It was not his contention that the government should abdicate itself of all schooling responsibilities, but that it should create a system in which it steps aside from the actual role of providing an education. The government would provide the funds for the parents, who would then send their children to the school of their choice.

This grant of public money would be the "voucher," and it would, in Friedman's view, give the parent the ability to control the education that their children received. Competition would then ensue, because as a school failed to meet academic standards the student would be removed and placed in a school which was meeting or exceeding those standards, thus ensuring that those schools lagging behind either caught up or closed down.

However, many opponents of Friedman saw this as a sure way to immediately resegregate the entire public school system. The voucher system while flawed would be acceptable, but only if it were much less of a free market oriented device. It was at this point in the early 1970's that the first regulated voucher system was introduced by Christopher Jencks. It was his contention that while vouchers could be an acceptable means of reform, there would have to be a governmental system in place which made 
certain that a framework of rules and regulations were in place to ensure that social vales and equality in selection of voucher candidates by the private schools was occurring. The two forms of voucher plans that emerged from these separate ideas and outlooks on vouchers were categorized by a private, free market funded form of vouchers and a general public form of vouchers which would be subsidized through the government.

This study proposes to determine what, if any, significant and immediate impact voucher programs have on student academic achievement as compared to those students in the same school district who do not take advantage of the voucher currently being offered. While many people assume there to be a direct relationship between the use of a voucher and academic improvement, much of the current research is in dispute as to the validity of this line of thought. The intent then is to as best as is possible shed light on the actual impact of vouchers on urban students in a selected school district.

\section{APPLICATION TO CURRENT SCHOOL}

As a teacher in a large urban school district in Ohio, the relevance of the research into the potential academic outcomes of students accessing voucher programs is quite significant. Whatever impacts the voucher programs currently in use in large urban school districts have on the students utilizing them, they will certainly be heavily scrutinized as to the legitimacy of their use for achieving academic improvement. From experience in an urban school district that just began to utilize a voucher system, the desire on the part of many parents is to see what impact the use of a voucher would have on their own children. 
The reaction to this by the schools is for now based partly on the current voucher studies, which have tended to be somewhat ambiguous in their results. Thus, it is in the best interest of large urban school districts to be making decisions about the use of vouchers based on current and statistically relevant information that can shed light on the academic benefits or downfalls of such programs. By doing this, genuine debate can take place within the community regarding whether or not they wish to implement school choice programs for their children.

\section{BIBLICAL INTEGRATION}

Almost all of the current research done on school vouchers programs makes some reference to the fact that aside from academic merits, the voucher is a way of creating equity in schools for those who do not currently have access to it. In this way, they hope to achieve a sort of equalized diversity and fairness for all those who are now disenfranchised by the current framework of most large urban school districts. However, while this study does not dispute the rationale for hoping to achieve equity and diversity through the use of vouchers, it does not find the same legitimacy for those goals when achieved from a humanistic viewpoint. Instead, the reasons for striving to achieve the noble goals of equality for all can be found in the purest form in the word of God.

The Bible makes it clear that it is a mandate for all who call themselves Christians to be actively engaged in looking for solutions to the inequities present here on earth. One of the most obvious examples of this is the life of Christ in the New Testament gospels. Repeatedly, we see Christ going out of his way to engage and restore those who were the most oppressed and downtrodden in the culture. Because each individual is 
uniquely created in the image of God, and is here on earth for a purpose, that person also has an inherit value and worth that is theirs in direct proportion to their creator. Therefore, the study has added significance when viewed in the light of the biblical mandate to show compassion to all those who are in need of assistance.

\section{PURPOSE OF THE STUDY}

The purpose of this study is to determine what, if any, significant academic achievement gains are made by those students in urban schools who choose to gain access to a voucher as opposed to those students who for varying reasons stay in the public schools and do not utilize the voucher provided. It will look at the current research being done in the field of vouchers and attempt to integrate this research into a comprehensive framework upon which any results garnered can be examined for validity. While research in the field of vouchers is abundant, there is no definitive consensus as to in legitimacy of vouchers when viewed in respect to academic gains acquired by those students utilizing them. Instead, much of this information is either contradictory or inconclusive when it addresses the academic achievement of these students. A comprehensive view of the studies done to date, along with an analysis of valid academic information gathered about students currently in an urban school district using vouchers seeks to imbue a more definitive conclusion to the currently conflicting evidence.

\section{EDUCATIONAL SIGNIFIGANCE}

Since the introduction of vouchers into the Cleveland school district in Ohio in 1996, there has been an ongoing debate as to the supposed benefits of such a program. 
For many educators and scholars, the immediate issue was whether or not the programs were even legitimately viable due to the separation of church and state issues raised by students leaving public schools to attend private institutions. This issue was resolved when the Supreme Court ruled in favor of the constitutionality of the schools, but it did little to dissuade those who legitimately sought to determine the actual effectiveness of voucher programs.

With the State of Ohio now fully implementing the use of the Ohio Graduation Test (OGT) in tenth grade, along with the use of the Ohio Proficiency Tests in elementary through high school, the ability to readily and easily track the academic records of those students leaving the public schools with vouchers should be easily accessible. Along with this is the recent mandate set foreword by the State of Ohio that requires all voucher recipients in the new "Educational Choice Scholarship Program" to continue taking the state achievement tests regardless of the school they attend.

\section{METHOD OF STUDY}

This study proposes to seek a possible correlation in the improvement or regression in academic achievement of urban high schools students now in parochial or private schools due to utilizing a state funded voucher, versus those urban students who remained in the public school system. The selected students will have been high school sophomores, and from the three high schools within the Toledo Public School District whose students were eligible to accept a state voucher during the 2006-2007 academic year due to their schools academic inefficiencies. 
For the purposes of evaluating the effectiveness of the voucher, the Ohio Graduation Test scores will be taken from the two different student populations. As this test is the same for all students throughout the state, the voucher student's scores should provide an indication as to how much of an immediate impact the voucher has had in relation to their public school peers academic performance on the same test.

The first set of test scores will be taken from students who were enrolled and completed their freshman year in one of the three voucher eligible Toledo Public High Schools during the 2005-2006 academic year, and then transferred into a private or parochial school as sophomores for the 2006-2007 academic year. These students will have taken the OGT test while enrolled as sophomores at one of the private or parochial schools. The purpose of this is to assure that this population of students shared one year of identical instruction with those students who remained in the public school system.

The second set of student OGT test scores will be drawn from the general population of the same three voucher eligible Toledo Public High Schools, and these students will have attended one of these schools for both the 2005-2006 academic year, and also for the 2006-2007 school year. These students will have shared in identical instruction throughout their freshman year with those students who then chose to utilize the voucher. It is hoped that from the results of the OGT test scores, an initial evaluation can be made as to whether or not the use of vouchers in urban high schools has had any immediate effects on those students utilizing them. 


\section{BRIEF LITERATURE REVIEW}

While the main goal of this study is to show if there is any measurable and accurate evidence of an improvement in student achievement by way of accessing vouchers, a large portion of the literature also deals with the issues of equity and choice that the voucher debate raises. Although these issues may at first seem to be peripheral to the issue of academic performance, they are in many ways an inseparable link to the issue of how vouchers can create this change in students' test scores. As Paul Hill (Hill, Campbell, and Koret Task Force on K-12 Education, 2002) noted, the outcomes of the debate on vouchers and school choice are serious, and they will have an impact on the students who utilize them. Therefore, the results that come from studies seeking to find correlations between academic improvement and the use of vouchers will either bolster or deflate the arguments and ideology surrounding the issue.

Many look at school choice (Costa, Elseginy, Lusco \& Pinney, 2003) as being the one issue that will define how student equity is achieved and ask if it is even necessary. If we are truly looking to find ways to create equality for students, and a chance for them to improve academically as well, it would seem that the direction one must move is towards some form of voucher system for those most in need (Dwyer, 2002). However, for many parents with children in the urban schools, very little if anything is known about vouchers, so it is of vital importance that they are at least informed about what the voucher is and could mean for their children (Walls \& ERIC Clearinghouse on Urban Education, New York, NY. [BBB00899], 2003).

Even staunchest proponents of the voucher system are willing to concede that it will not be a perfect solution for the students who are in the urban schools. Yet they also 
believe that it is better than doing nothing (Peterson \& Campbell, 2001) and assuming that people don't really want change. In fact, they argue that reform in the way of school choice as delivered through vouchers is exactly what most people want (Kirkpatrick, 1990). For those who look to find a solution through vouchers there much be a way to achieve the long-term goal of increasing not only student performance but also Student's perceptions regarding their own ability to perform will academically. This will have the intended ripple effect of creating test scores (Forman, 2004) that show positive improvement.

For others though, the problems in many of the voucher debates seem to be more real than some would like to imagine. What about those students that are left behind and do not have access then to the better schools? In a study looking at this effect in the Cleveland voucher programs (Paul, Legan, \& Metcalf, 2003), it was determined that from those eligible students who did not use or accept the voucher, and majority were lower income minorities. If this is the group that is supposed to be targeted, it does little good if they are not participating in the program. Likewise, with the passing of the No Child Left Behind Act (NCLB), the stakes become increasingly higher for those students that are left behind.

One of the issues addressed by Fredrick Hess and Chester Finn is that with NCLB, the choice mechanisms put in to place are unlikely to cause schools to increase their achievement levels. And if schools are going to make reforms to try and meet the needs of their students, it will take time. Many reformers (Reyes \& Rodriguez, 2004) who seek to bring about equality in the urban schools but shy away from school choice options, see it as an issue that can be solved if the management of the schools systems 
were rethought and decentralized. With so many views about what the real effects of a voucher programs are on urban students, a need has arisen for significant information as to what the real effect on student achievement has been for those already utilizing a voucher system.

\section{THE TEST RESULTS}

From the studies that have been produced to date, there does not seem to be a clear result as to what effect the use of a voucher has on student achievement. One of the most comprehensive studies to date conducted by William Howell, Patrick Wolf, David Campbell, and Paul Peterson (Howell, Wolf, Campbell, \& Peterson, 2002) studied the performance of students accepting vouchers in three large urban school districts. The results from the study showed that there was a statistically significant increase in the student achievement test scores of African-American males in each year of the program. The statistics did not show any gains for other minority groups using the vouchers in the same cities.

In another book looking at the same statistics, (Howell \& Peterson, 2002) the researchers found that a significant achievement gap did exist between those students leaving the urban schools with vouchers and those remaining in the public schools. But, the study noted that the true effect of vouchers on the students was limited by the small sampling of students participating as compared to the large number of students still in the public school system. However, critics (Krueger \& Pet Zhu, 2004) have argued that the methods used in the study did not adequately account for variables such as a lack of 
follow-up testing for students who took place in the study and were effected by the way that race and ethnicity was defined in the study.

In response to this assessment, Howell and Peterson responded (Peterson \& Howell, 2004) by defending the use of their data as collected and the interpretations that were gathered from their baseline results. In one of the earliest voucher studies that came out of Milwaukee (Hess, 2002), little measurable data was garnered due to lack of cooperation by varying elements within the city schools administration and unions. The most thorough analysis of the Milwaukee voucher program (Witte, 2000) indicated that after three years in the program little academic difference existed between the students and their counterparts in the Milwaukee Public School System.

In the Cleveland voucher program that has been in existence in some form since the mid-nineties, a recent study (Study: Voucher students perform same as public School Peers, 2004) by the University of Indiana indicates that there is no significant difference between those in the public school system and those utilizing the voucher. The results of the studies to date indicate that more analysis and data collection need to be performed in order to lend relevancy to the numerous and widely varying outcomes of voucher programs in relation to their impact on student academic performance.

\section{DEFINITIONS}

Voucher - For the purposes of this study a voucher is a certificate by which parents are given the ability to pay for the education of their children at a school of their choice, rather than the public school to which they were assigned. 
NCLB - "The No Child Left Behind Act, or the Reauthorization of Elementary and Secondary Education Act (ESEA) was enacted January 8, 2002, to expand choices for parents focus resources on educational methods, and provide accountability for results." ("No Child Left Behind," 2004)

OGT - Ohio Graduation Test. A compulsory test given to all Ohio students in the spring of their sophomore year of high school. It consists of 5 individual tests covering: Reading, Writing, Math, Science and Social Studies. Students must pass all five sections in order to receive their high school diploma. Students who do not pass any of the five tests have four more opportunities to pass those sections they have failed.

\section{SUMMARY}

This study hopes to determine what, if any, significant and immediate impact a voucher program has on urban high school student's academic achievement as compared to those urban students in the same school district who do not take advantage of a voucher currently being offered. The fact that much of the data currently available in this area is either conflicting or inconclusive leads one to believe that there is still ample room within the field of study to conduct further research into the matter. And while there is no guarantee that the data collected from this study will prove voucher students to be more successful than their peers who are in the urban public school, it is in the best interest of all involved to determine as best as is possible whether or not vouchers are helping to achieve academic equity for those urban high school students currently utilizing them. 
Unfortunately, during the course of gathering and completing my research for this thesis project I was refused access to the largest and most relevant pool of data needed to make a comprehensive statement about the efficacy of the voucher program being studied. This was due to the refusal to release student OGT test data on both the part of the Ohio Department of Education and certain parochial schools participating in the Ohio EdChoice voucher program. Although the parochial schools had initially indicated they would cooperate in this study, when the actual student test data for the OGT was being gathered it became apparent that they were no longer willing to participate.

Likewise, the Ohio Department of Education was unable to further help me gather the student data needed, citing student confidentiality issues. Repeated attempts on my part to obtain the test data from the ODE went unanswered, despite citing specific FERPA exclusions ( 34 CFR § 99.31 ) that allow for access to student data without parental consent. Regardless of these issues, it is my belief that even if no direct connection can be made regarding the immediate impact of vouchers on student academic achievement, or the limited date available should prove to make this papers outcomes inconclusive, the study will continue to help guide those who may also be seeking similar answers and direct them into new avenues for possible research into the matters presented. 


\section{LITERATURE REVIEW}

As more school districts both urban and rural face an overwhelming onslaught of dwindling state finances and declining student enrollment, the role of alternative schooling and publicly funded voucher programs continues to stir public debate. The idea that the problems of inequity faced in urban schools can be solved by a system that offers free or partially subsidized tuition to the school of your choice is to many people a radical idea. To a majority of people who have always viewed the public school system as a bastion of democratic idealism, this notion that a system based on selective segregation can achieve positive results runs contrary to their own very notion of what public schooling should look and act like.

Still, the voucher movement continues to grow, with the number of cities, states, and individuals using the voucher option becoming more widespread each year. Ideally then, one would hope to see a very clear indication that something as controversial as vouchers in urban schools pays dramatic and even immediate dividends for those students utilizing the programs. Yet, the data on the immediate impact that vouchers in urban schools have on students is far from definitive. This study then hopes to add a more substantive analysis of the impact that these programs can have on students currently accessing vouchers specifically in urban schools.

Recently the State of Ohio voted to not only continue their support of a voucher program currently ongoing in the city of Cleveland, but they also broadened the program to include more schools and more state funding. It would seem that with voucher 
programs gaining more acceptance and widespread use, it is inevitable that they will continue to become an integral part of our modern education system. In light of recent attempts such as this to expand and modify the scope of voucher programs in public school districts, it is only fitting that a fair analysis of the different views in favor of and in opposition to such voucher programs be taken into consideration. What was once something that many people were only vaguely aware of has now become a flash point in the debate and battle over the possible future of public schooling as we have come to know it.

The heart of the voucher debate stems from the very idea of what a voucher is and how it should be utilized. The first person to actually suggest the use of such system was the well known economist Milton Friedman, (Moe, 2001, p.17) whose idea of vouchers when presented in the early 1960 's was one based on the view that public schools were essentially a government run monopoly with very little incentive to produce a high quality education. It was not his contention that the government should abdicate itself of all schooling responsibilities, but that it should create a system in which it steps aside from the actual role of providing an education, and instead provide the funds for the parents who would then choose the school of their choice.

This grant of public money would be the "voucher", and it would, in Friedman's view, give the parents the ability to control the education that their children received. Competition would then ensue, because as a school failed to meet academic standards the student would be removed and placed in a school which was meeting or exceeding those standards, thus ensuring that those schools lagging behind either caught up or closed down (Moe, p18). David Harmer (1994, p. 175) emphasizes this point when he says: 
By replacing compulsion with competition, school choice makes the schools far more responsive to individual needs and desires, and it gives both the parents and students a sense of ownership, of investment, in their schools. It depoliticizes the schools. In politics, one side wins and one side loses, and the winners get to set the policy. In a free market, each participant's needs can be met in different ways, and nobody gets to set policy for anyone else.

Scott Abernathy (2005) expounds on this idea when he reiterates what John Chubb and Terry Moe saw as the fundamental problem in a democratically controlled public school system. That is, because the system itself is a democratic one where everyone from the school board to superintendents is freely elected, a bureaucratization soon follows. According to Abernathy, the results of this bureaucracy inevitably lead to lower performing schools. Even though systems are in place to prevent these types bureaucratic entanglements, the fact that they are already a part of the system means that they inevitable end up "feeding the beast".

Private schools on the other hand are able to supersede this malaise with a highly structured organization resulting in better performing schools. Even some of those reformers opposed to broad school choice plans (Reyes \& Rodriguez, 2004) have shown an increased desire to try to create an equality in schooling based on a systematic decentralization and rethinking of how schools are managed. This would fall in line then with Milton Friedman's assumption that, short of overhauling the entire public school system, success cannot happen and therefore parents must be given the right to choose for themselves. 
As apparent as some may find these arguments, critics such as Ronald Corwin and Joseph Schneider (2005, p.49) are quick to point out that this educational bureaucracy, while often the focal point of criticism, serves a definitive purpose. What they say critics fail to mention are all of the disastrous examples of failure and abuse that are often rampant in the free market system. While a business may be able to declare bankruptcy and start with a clean slate, schools risk much more when failure and mismanagement occur on a comparable scale. This position is further clarified when Corwin and Schneider (2005) say:

...Business and public education alike will be, indeed must be, constrained by laws and rules. We recognize that there are some awful rules that are unnecessarily cramping public schools and adversely affecting students. However, it isn't necessary to scrap everything to change them. (p. 50)

Also, many opponents of Friedman saw the free-market approach as a sure way to immediately re-segregate the entire public school system. They were looking at many school systems that were just emerging from landmark civil rights victories in the judicial court system, and already it seemed as though much of this progress may be reversed by an attack through a capitalistic voucher system perceived to benefit those who already had the most freedom within the public school system. As Brighouse points out (2000), for these critics the commodification of the education system would be enacted when the distribution of education became subject to market driven forces.

The voucher system while flawed would be acceptable to some of its critics, but only if it were much less of a free market oriented device. And this feeling of education 
somehow becoming a commodity is reiterated when Alex Molnar (Brighouse, 2000) is quoted as saying:

Over time, market values have eroded and debased the humane values of democratic civil society. Listen closely to the language of commerce applied to human relationships. Children are defined as 'future customers', 'future workers' and 'future taxpayers' ... When the logic of the market is allowed to dominate society, relationships are inevitably turned into commodities to be bought and sold. (p.47)

It was this type of general idea that led us towards first regulated voucher system, (Moe, 2001, p.21) which was introduced in the early 1970's by Christopher Jencks. It was his contention that while vouchers could be an acceptable means of reform, there would have to be a governmental system in place which made certain that a framework of rules and regulations were strictly followed to ensure that both social values and equality in selection of voucher candidates by the private schools was occurring (Moe, p.22). Instead of letting some uncontrolled and highly unregulated form of capitalism run rough shod over the education system, Jencks looked to use governmental regulation of the vouchers to achieve the social and societal reforms many felt were essential to a strong education. The two forms of voucher plans that emerged from these separate ideas and outlooks on vouchers were categorized by a private, free market funded form of vouchers and a general public form of vouchers which would be subsidized through the government.

From these two original, yet differing concepts of how a voucher system should look and act, has emerged the system that is generally used today in various forms 
throughout the country. However, at the heart of the debate about whether or not vouchers should even be considered are a few fundamental differences that cut to the core of the arguments for and against both sides of the issue. In many ways, the voucher issue is one that quickly divides its supporters and detractors based on fundamental ideological and political views (Witte, 2000, p.159). In this climate of partisan rancor, the key differences between what is right and what is wrong with vouchers have arisen.

One of the first and most obvious questions to arise from the debate centers on the inevitable interpretations of choice. What does it mean to those who are able to make choices about where they are educated and those who cannot, and do parents have the right to decide what school they wish to send their children to, despite the geographical constraints often placed on them by a school districts boundaries and location (Sarason, 2002, p.88)? Certainly most would agree that choice is a democratic imperative, yet for many children in urban school districts, this choice is non-existent. They have neither the means nor the resources to relocate to a "better" school district. It is this type of situation that voucher advocates claim all but demands a way of subsidizing those families that are forced into failing school systems.

This case can be especially true when you are in a situation that creates dramatic constraints on your ability to have a choice in where your children attend school. According to Peterson (2003), 45 percent of whites choose the neighborhood in which they reside based on the schools, as opposed to only 22 percent of African-American families. These numbers are especially useful when one considers the effect vouchers can have on choice in terms of the parents of children who might possibly be leaving a failing school. Parents are the real decision makers in this entire process, and therefore it 
is in their best interest to make decisions that will have the most positive outcome for their children.

Yet, as much as some would assume parents would only choose the highest achieving schools for their children when given the opportunity to choose freely, this is not always the case. Due to many other influential factors, the decisions are often vastly different depending on the race and economic status of those choosing. Kemerer and Sugarman (1999, p.78) noted that in a study of school choice in Montgomery County, the evidence indicated that both white and minority parents chose schools were their children would be racially and socioeconomically less isolated. This then has the potential to lead to a system of segregation by choice, where the minority families often choose schools in low-income neighborhoods, of which the vast preponderance are lower achieving than there respective suburban counterparts.

Along with this choice comes the implication that parental decisions about schooling will have a direct and proportional impact on the level of parental involvement that takes place in any given school. Studies in San Antonio Public Schools have shown (Godwin \& Kemerer, 2002) that when parents felt the public school system treated their children in an unfair manner, the level of parental involvement dropped dramatically. On the other hand, when given a greater say in the choice of schools, parental involvement increased dramatically.

The negative side that then arises from the school choice debate is the question surrounding what happens to those children who are left behind in the failing schools. The same research done by Godwin and Kemerer (2002) in the San Antonio school districts tended to show that there was little long-term negative impact. While there did 
seem to be a statistically significant drop in math scores on standardized tests over a short-term period, the research also seemed to indicate that standardized test scores declined less rapidly for those who remained behind in the regular schools.

While this may suggest that the overall effect of vouchers on students has only moderate impact when extended over a long period of time, it fails to take into account the respective and varying levels of education being produced in the private sector versus the public, and the immediate need for many of these students as perceived by themselves and their parents to "catch up" to those utilizing a voucher. If a student left behind in a poorly performing public school scores lower on a standardized achievement test at any point, it may be difficult to ask that parent or student to persevere with the assumption in mind that over the course of his or her academic career this student should catch up to their peers who are currently utilizing vouchers and private educations. According to these studies, the choice factor in the education process is one that can have a substantial positive impact on the performance of students attending schools that they have gained access to due to the help of vouchers (McGroaty, 1996).

This however brings up a similar and even more compelling issue, which is whether or not a voucher system would eventually become a tool for promoting a newly minted version of educational stratification based on race and wealth, or a means of achieving real social and educational integration. The effect that is most often spoken of is one that Terry Moe (1995, p.23) refers to as skimming. In this scenario, the families with the most knowledge, money, and potential gain from the use of vouchers are able to take full advantage of the opportunities presented. 
Private schools that would be accepting this voucher are then able to "skim" the cream off the top of the voucher crop, effectively closing out those who are most in need of the voucher assistance and schooling it would provide (Moe p.23). There is certainly a basis for truth in this idea, as more often than not, a higher level of education and wealth accompanies a higher concern for the educational needs of one's children. As Michele Forman, a high school teacher in Vermont stated "We have one system of education for the middle class and the affluent and the rich and we have a second system for everyone else" (2004). The question then becomes whether or not "everyone else" will eventually have a place at the education table, and how exactly their place will be secured for them. The current voucher system, while seemingly open to helping solve this inequality, does not always build a bridge to the better schools the underprivileged may be dreaming of attending.

Often, both private and parochial schools which are drawing students from this pool of potential voucher students will effectively "skim" these students by asking for academic and personnel files from the public schools these candidate students are attending. In cases like these, any hidden issues such as academic deficiencies or school discipline problems become an immediate barrier to a student's acceptance, regardless of the voucher that they are holding. As is often the case in parochial schools, the administrators will seek the right to screen those students who are using a voucher (Morken \& Formicola, 1999, p. 205), thereby taking away from both the parent and student, the very purpose for which the voucher as intended. In essence, the schools have then become just another barrier to achieving academic equality. What was supposed to 
be their purported reason for accepting vouchers to begin with has thus become the reason they will not accept a particular student.

Yet, the concerns over skimming are also seen by many as somewhat reactionary if one considers who would be most likely to be using the vouchers. Most of the time, those families with the access to information are already sending their children to a school that they would want them to be attending, whether it is private or public. In most of these cases, "the cream-skimming might occur in some instance, but the skimming is done from a decidedly small bottle" (McEwan, 2004, p.69), indicating that this is certainly not an epidemic created by voucher programs. As John Merrifield (2002) points out, the way parents choose schooling today often mitigates segregation, because the parents desire for specific programs and activities overreaches any interest in a homogeneous student body. A recent study that re-evaluated the effects of choice was conducted in New York City School Districts 1 and 4 by Schneider, Teske, \& Marschall (2000, p.222). In their study, they concluded that while the ideal of having a racially and socioeconomically diverse school system is not usually achieved in America, the reality is that choice does not significantly increase the level of stratification in either of these areas.

Inevitably, there will always be a certain amount of segregation that occurs within any school system, as it is built into the very nature of how we determine who attends schools. By using invisible boundaries on maps to define who can and cannot attend certain schools, those parents with the economic means to achieve mobility will choose the school that best fits their desires. The reality of the situation can often fall 
somewhere in between on both sides, because very few people either in support of vouchers or against are looking to create a segregated classroom.

Even so, there cannot really be a serious problem with segregation in the schools if the majority of private and religious schools refuse to accept vouchers. This too has been a sticking point for many concerned with the equity issue of vouchers from day one. What good, they argue, will vouchers due for a young African American if the voucher he or she receives is not accepted in any of the schools they would like to attend (Cookson, 1996)? This is of course a serious concern, as there would seem to be no apparent and compelling reason for many of these private and parochial schools to accept such vouchers. The money that they can receive from a voucher may or may not be worth the perceived risk that the school assimilates by taking on students that they know are already behind academically.

In the majority of cases the schools are well aware that the voucher will not fully cover the tuition costs of the student, and in most of these situations the student will have little or no access to the extra money needed to cover the remaining tuition balance (Kahlenberg, 2003). Critics argue that this financial gap then becomes the most prominent reason for the schools to deny access for voucher candidates. As it often is, many of the private schools have no immediate need for the student's money, and the parochial schools while often desperate for tuition money, will most often not take a loss on a student who can only pay for a portion of the bill. Kahlenberg (2003) also raises the issue of the private and parochial schools hesitancy to accept these vouchers due to the fear that their schools would over time come to resemble the public schools that so many of the voucher students were trying to escape. Even though most schools deny having 
special admission requirements (Corwin \& Schneider, 2005), they often take into consideration things like student attendance, academic records, and recommendations. In many ways the voucher then becomes a Catch-22 for the schools. If they choose to accept the voucher, they are bearing the burden of a possible financial loss and the real possibility of a drop in academic achievement within their student body. Yet, if they deny vouchers to the minority students who are applying, they not only suffer in the face of public scrutiny, but they also deny the very values and ideals that they most often use to define their schools mission.

Also, as vouchers become more widely available it is quite possible that a new crop of private and charter schools may begin emerging with the sole intent of accepting the specific value of the voucher as full payment for tuition costs. There certainly is no guarantee that this outcome will prevail, but this was exactly what free market economists such as Milton Friedman saw as the necessary evolution of the system. It would, in essence, be analogous to the voice heard by Kevin Costner in the film Field of Dreams, calling out "If you build it, they will come."

Proponents of the voucher programs argue that what the most critical opponents of school choice fail to take into account is that the overriding aim of most private schools is to advertise their education as one which is academically, socially, and racially diverse. In today's environment of political correctness and racial harmony, any hint that a school would deny vouchers based on economic or racial guidelines would serve as a possible deathblow to that school (Hess, 2002). Moreover, (McEwan, 2004) supporters argue that the growing demand by voucher recipients as the programs expand will force private schools to participate, or else succumb to falling enrollment while other schools 
pick up those not accepted. The market will, according to the free market system, be the overriding incentive to not shut ones doors to the growing school choice demand, along with the possible ramifications of being seen as an institution denying access to minority students.

Critics of the free market approach such as Corwin and Schneider (2005) point out that there is actually much more to choice policies than simply race and class, and that the private schools engaging these students are not always particularly chosen for their academics anyway, and are not usually seen as being closed to minorities. For many of those seeking to use a voucher, the determination has been that the public schools are actually the ones that are inequitable (2005). These parents also see the voucher as a way to move their child from what is often a violent or impoverished neighborhood.

In both these regards, the underlying reality of choosing to either submit an application for a voucher or to stay in the public school has little to do with any perceived racial bias. Instead, equity for the child is the main motivating factor for change. In fact, many critics argue that most of the stereotypes about why parents even investigate vouchers and choice programs are contrary to the actual realities that underlie the reasons for parents to move their children in the first place. So, the argument is not towards why parents are concerned about their children

Still, at the present moment there simply are to few voucher programs of adequate size operating to make concrete statements regarding the possible acceptance or denial of students based on factors such as race. Any evidence either for or against the acceptance of students due to these programs will have to be gathered and then viewed in light of 
how many schools both private and parochial begin accepting the vouchers once they are offered. But what we are seeing as this evidence emerges, is that it will bring with it another even more pressing issue that surrounds the voucher, and that is the continuing arguments about the validity of the current data regarding academic improvement.

From their very inception, one of the most intensely debated topics concerning vouchers has surrounded the validity of the test data as it relates to the achievement gains claimed by some of the more ardent supporters of vouchers. From the beginning of the early testing programs, it was understood that the collection of data as it relates to test score variations from students old schools to their newly voucher funded private schools would be a critical component in determining the viability of the voucher programs. Specifically of interest was the effect vouchers would have in the urban school districts. Much of the research to date has focused on these key areas, as they were the ones that held the most promise for the hopes of creating equitable schooling for those in the most need.

The earliest and most controversial research came from a study conducted by William Howell and Paul Peterson. They concentrated on evaluating the test score data taken from students who had utilized voucher programs in several large, urban, metropolitan cities. Specifically, Howell and Peterson (2002, p.34) looked at the results from Dayton, Ohio, New York City, and Washington, D.C. In each of these cities the voucher recipients were picked from a controlled lottery, meaning that they had to meet specific financial needs, and agree to the terms of the voucher. Most of the students attended private religious schools, and in almost every case the voucher had to be 
supplemented by other financial means in order to pay the remaining amount of tuition not covered by the voucher (2002).

The statistics that they were able to extrapolate from the data as it concerned test scores over a three-year period were rather significant in regards to African American children in the lower elementary schools. In the first year only New York City saw any noticeable gains in test scores for African Americans, but after the second year significant gains were noticeable in all three cities (Howell \& Peterson, 2002, p.146). In year three in New York, these same students test scores were again statistically significant (2002), yet the year three scores in Washington, D.C. were not of any statistical impact, something that Howell \& Peterson were unable to account for. Based on the initial evidence from test scores, it would be fair to at least assume that for a specific segment of society, the academic impact of a voucher program can be significant.

However, this data was later questioned by Krueger and Zhu (McEwan, 2004), who took exception to the validity of the sample, noting that many of the test numbers fell into the statistically insignificant range after their own comprehensive analysis of the statistics. It was their conclusion that many of the students' scores could simply not be ranked as significant, and therefore the data could not be classified as showing any quantifiable measure of improvement.

Another study mentioned earlier in this paper conducted by Schneider et al. (2000) in New York City School District 4, showed that academic improvements were shown to have measurably increased for sixth grade students in both math and reading proficiency when compared to those districts not allowing for school choice. This data was more reliable than earlier test results that had shown improvements, because it took 
into consideration many of the variables such as smaller school size and new students brought in from higher socioeconomic backgrounds. They make a point of addressing the specific concerns in their testing methodology regarding such effects as better leadership, school flexibility, and the retention/attraction of better students (p.198). There conclusion was that choice for the students was the overriding factor in the improvement of test scores when the district was compared to other New York City Districts having similar levels of disadvantage but no access to school choice.

Still, many studies continue to refute the positive findings that have been presented. The most recent study of the Cleveland voucher program (Study: Voucher students perform same as public SchoolPeers.2004) carried out by the University of Indiana indicated that there was no significant testing difference between students utilizing the vouchers and those remaining in the public school system. This data is in contrast to previous studies that would have seemed to indicate a positive result in student testing numbers in the Cleveland voucher program. It is this dispute of the interpretation of data by academic institutions and researchers such as Krueger and Zhu that brings into focus one of the more difficult aspects of determining the significance of such research.

At the moment, the amount of long-term viable research is very limited due to the relatively small amount of voucher programs currently in place (Hoxby, 2003). Joseph O Keefe (Wolfe, 2003) notes that:

In places where voucher programs have been established, gains in academic achievement for voucher recipients are not consistent enough or conclusive enough to warrant wholesale adoption or rejection of the practice. Most plans are 
not consistent enough and studies not comprehensive enough to provide comparative evidence about key questions...(p.198)

Another factor that plays a key role in determining the amount of achievement by any one program is the actual participation of the schools and city that are providing the vouchers. In the early stages of the Cleveland voucher program (Hess, 2002), the limited availability of the vouchers and the strong opposition of their use by the unions in the Cleveland Public Schools system all but undermined the ability of the program to produce any meaningful results. This one factor has been the continuing obstacle that the voucher programs have most often struggled to move past.

While critics argue that there have not been enough long-term voucher programs in place to adequately asses the true impact of such experiments, large cities with urban school districts often fear what the outcomes might be if these programs fail, and thereby often refuse to participate in any long-term programs (2002). Among those districts that do choose to participate, the choice of the voucher is often limited to a segment of the districts population, such as in the city of Toledo, Ohio. The states education voucher system has determined that only those students in schools that fall under the classification of "academic emergency" over three consecutive academic years are eligible to receive a voucher. This means that while three high schools in the Toledo Public School District qualify, four other district high schools do not meet the criteria. And although not meeting the criteria for failure would in most observers analyses be a positive for those high schools, it by default leaves many students who may wish to utilize a voucher without any form of recourse. 
Specifically salient in districts such as the Toledo Public Schools where high school students are eligible for these vouchers, is the question of whether or not the voucher provides any immediate academic impact for the students. If students are being given vouchers at such late stages in their academic careers, one would hope to see immediate academic improvements. Otherwise, an argument could be made that not only will the students have little or no time to fully realize any academic benefits stemming from their use of the voucher, but that the money provided for the voucher is of no real benefit to anyone but the schools accepting them. Until more specific studies can be evaluated, the academic impacts of voucher programs will remain a point of contention for those on both sides of the issue.

In cases such as these, it becomes rather apparent that compromise must be reached on some level if the case either for or against voucher programs is ever to have fair a trial. As Stephen Sugarman and Frank Kemerer (1999, p.101) point out, choice proponents are correct when they insist that the school system currently in place has failed in many significant ways, but at the same time they fail to take into account the fact that market approaches to education do not give us the freedom to essentially give up on the current system. Sugarman and Kemerer realize that "This suggests the wisdom of a policy approach that is unhurried, reasonably cautious, and tied to specific circumstances and that pays attention to articulating the public interest in supporting education and building healthy institutions of governance" (p.101). In order to move forward, we must seek compromises that are reached through utilizing viable working solutions based on demonstrated long-term results. 
This will also mean that at some point these programs will have to emerge from what so far has been in the grand scale of public education, a relatively small but growing existence. As vouchers continue to stir debate in both the public and private sectors of education, it seems that it is indeed inevitable that when some form of compromise has been reached on the issue, the public will have the opportunity to see for themselves what the immediate and long term viability of a successful full scale voucher program will be for those students most in need of true educational reform. 


\section{DATA ANALYSIS}

The purpose of this study was to determine whether students from the Toledo Public School District that used the Ohio EdChoice voucher program showed any immediate improvements over those students who did not access the voucher, but remained in the public schools. The data acquired and used for this study was based solely on the test results taken from the Ohio Graduation Test, which for the purposes of this study were taken by students who were sophomores during the 2006-2007 academic year. This was the first academic year that students in specific Toledo Public Schools were able to utilize a voucher. There were three high schools within the district whose students were eligible for the EdChoice voucher based on the criteria of a their public school being in the either "academic watch" or "academic emergency" for two out of the last three years as defined by the state of Ohio.

Out of the three high schools that met this eligibility requirement for access to the EdChoice voucher system, only two schools had students who actually applied for and participated in the program. And, out of these two, I have only utilized data for OGT test results from one school, which will be referred to throughout this chapter and in tables as high school 1. This was due to the limitations that I came across as briefly described in the summary in chapter one.

Of the thirty-five EdChoice voucher students from the two Toledo Public high schools who met the criteria for this study, I was only able to acquire the necessary OGT 
test results for three students. However, one of these students was, upon further review, found to have been a Toledo Public High School student for two years prior to enrolling in the EdChoice program. This meant that while officially the student was listed as being a sophomore at the time they took their OGT test, they were excluded from the study because they had had two years of instruction in the public high school as opposed to the study groups one year. Both of the remaining students in my study attended the same EdChoice qualifying high school as freshman, resulting in the use of only one public high schools OGT test data.

In determining whether or not the EdChoice students showed a significant improvement over their public high school peers, I first collected the OGT test score data from high school 1 for the 141 students who qualified as sophomores and had attended only one year in that same public high school as freshman. From this sample set, I was able to determine the mean score for the entire sample group for each of the five required sections of the OGT test. The five tests as shown in Figure 3.1 compose the five "core" academic competencies the state requires each student to be at least "proficient" in so that they may pass that section of the test.

OGT Core Knowledge Tests

\begin{tabular}{|l|l|l|l|l|}
\hline Reading & Math & Writing & Science & Social Studies \\
\hline
\end{tabular}

Figure 3.1 The five core knowledge tests

The OGT test has a specific scaled score range which determines the five levels at which a students knowledge and proficiency of the subject can be determined. These scores and 
their correspondingly acquired "proficiency" for the spring 2007 OGT test are shown in Table 3.1.

OGT scaled score ranges for all subjects and performance levels

\begin{tabular}{|c|l|c|}
\hline Subject & Performance Level & Scaled Score \\
\hline \multirow{5}{*}{ Reading } & Advanced & $448-549$ \\
\cline { 2 - 3 } & Accelerated & $429-447$ \\
\cline { 2 - 3 } & Proficient & $400-428$ \\
\cline { 2 - 3 } & Basic & $383-399$ \\
\cline { 2 - 3 } & Limited & $260-382$ \\
\hline \multirow{5}{*}{ Writing } & Advanced & $444-555$ \\
\cline { 2 - 3 } & Accelerated & $425-443$ \\
\cline { 2 - 3 } & Proficient & $400-424$ \\
\cline { 2 - 3 } & Basic & $384-399$ \\
\cline { 2 - 3 } & Limited & $250-383$ \\
\hline \multirow{5}{*}{ Science } & Advanced & $476-560$ \\
\cline { 2 - 3 } & Accelerated & $430-475$ \\
\cline { 2 - 3 } & Proficient & $400-429$ \\
\cline { 2 - 3 } & Basic & $378-399$ \\
\cline { 2 - 3 } & Limited & $276-377$ \\
\hline & Advanced & $445-608$ \\
\cline { 2 - 3 } & Accelerated & $425-444$ \\
\cline { 2 - 3 } & Proficient & $400-424$ \\
\cline { 2 - 3 } & Basic & $371-399$ \\
\cline { 2 - 3 } & Limited & $212-370$ \\
\hline \multirow{5}{*}{ Social Studies } & Advanced & $446-626$ \\
\cline { 2 - 3 } & Accelerated & $429-445$ \\
\cline { 2 - 3 } & Proficient & $400-428$ \\
\cline { 2 - 3 } & Basic & $382-399$ \\
\cline { 2 - 3 } & Limited & $231-381$ \\
\hline
\end{tabular}

Table 3.1 Score ranges and performance levels for all subjects

From these scores, a "proficient" score of 400 or greater is required to officially pass each core knowledge section of the OGT. As the purpose of this study was only to determine whether or not a significant improvement in student test scores was achieved by those students utilizing an EdChoice voucher, the test score as it relates to an individual EdChoice students "proficiency" should not be considered relevant except when compared to the mean score of the overall sample group from high school 1. 
The mean scaled scores and the standard deviation for each score of the sample group from high school 1 are listed according to each of the five academic categories in Table 3.2.

Mean scores and standard deviation for High School 1 in all core subjects

\begin{tabular}{|c|c|c|c|c|}
\hline Reading & Math & Writing & Science & Social Studies \\
\hline Mean $=404$ & Mean $=399$ & Mean $=409$ & Mean $=388$ & Mean $=393$ \\
$\mathrm{sd}=8$ & $\mathrm{sd}=10$ & $\mathrm{sd}=8$ & $\mathrm{sd}=12$ & $\mathrm{sd}=9$ \\
\hline
\end{tabular}

Table 3.2 Mean scaled scores and standard deviations for high school 1 core subjects

This table shows that while not proficient in all core areas of the OGT, when adjusted for the standard deviation, a majority of the high school 1 students would be passing all core subjects of the OGT test. With this in mind, the individual scaled scores of the EdChoice voucher students were to be taken as a sample group and then the mean for that sample, as well as the standard deviation, would be compared to the high school 1 student scaled scores. For the purposes of this study, a voucher student would need to show a statistically significant gain in a majority (meaning 3 out 5) core subject areas. A statistically significant gain would constitute a score above the high school 1 mean score after adjusting upwards for standard deviation in any of the core subject areas. No multiple independent variables would be necessary as the test scores from each group were only going to be compared directly to one another. In doing this it was hoped that a reasonable determination could be made as to the actual efficacy of whether student test scores are improved when a voucher is made available to students in poorly performing schools, and if this improvement is immediate. 
However, due to both untimely and unfortunate circumstances, I was able to only acquire the scaled OGT scores for 2 of the 35 EdChoice voucher participants. Because of this, I was unable to complete a statistical computation for the mean and standard deviations of the voucher student group scores, and have instead made the decision to list each of the two students individual scaled scores for each core subject area in Table 3.3 and 3.4.

Student 1 Scaled Scores

\begin{tabular}{|c|c|c|c|c|}
\hline Reading & Math & Writing & Science & Social Studies \\
\hline 428 & 400 & 413 & 385 & 403 \\
\hline
\end{tabular}

Table 3.3 Student 1 scaled scores

Student 2 Scaled Scores

\begin{tabular}{|c|c|c|c|c|}
\hline Reading & Math & Writing & Science & Social Studies \\
\hline 411 & 413 & 409 & 382 & 398 \\
\hline
\end{tabular}

Table 3.4 Student 2 scaled scores

The test scores for both students would indicate that they are performing, at or slightly above, their counterparts in the public schools. Both students have passed at least three sections of the core subject areas, scoring within the proficient range in each of those subject areas, but not above that performance level. Based on the previously established criterion for showing significant improvement, neither student would meet the proposed standard with their current scaled scores. However, due to the lack of 
sample size, a true indication of academic improvement, or lack thereof, is impossible to obtain at this time.

What is known of the acquired scores is that they are representative of the fact that those students in the public school listed in "academic emergency" or "academic watch" are extremely close to showing a proficiency in a majority of the core subject areas. As was indicated by the mean of the scaled scores, they are only one point in math and seven points in social studies from achieving a proficient rating, and when adjusted for standard deviation, they are passing four out of the five subject areas.

As for the EdChoice voucher students, a more comprehensive picture of their scoring will need to be completed to further reveal the possible benefits in academic achievement currently being propositioned by many both inside and outside of education. Because the OGT is used to evaluate the acquisition of subject knowledge for students in the state of Ohio, it provides a controlled variable providing for excellent data acquisition, and the use of that data for future research will most certainly continue to grow. Unfortunately for my study, the timing to pursue such an answer is no longer available, and the final cooperation necessary was lacking. 


\section{CONCLUSIONS AND EXPLANATIONS}

The actual outcome of this study was significantly hampered by the last minute inability and refusal of both schools and state agencies to provide me with the pertinent information needed to make a statement regarding the possible efficacy of voucher programs as they relate to the immediate academic gains for those students accessing them. However, I have still determined that there are a number of both important and revealing conclusions about the EdChoice voucher program and how it affected my subsequent attempt to study whether or not this program performed in ways highly anticipated by many of its advocates. Although an insight into the purposed academic benefits of the EdChoice voucher program was always the direct intent for the outcome of the study, the resulting lack of information to be gained played a significantly large role as to what recommendations may be suggested for further studies into this particular subject.

While several studies have indicated that significant academic improvements occur when elementary students in urban settings utilize vouchers over extended periods of time, the same cannot be said for urban students in high school settings. Specifically called into question in this study was the rationality of allowing urban high school students access to vouchers that cost taxpayers thousands of dollars per pupil. The consensus of voucher studies to date indicate that the time frame necessary to see significant academic achievements is not attainable for the majority of students who 
would use a voucher to attend a private high school, as they often have two years or less remaining before graduation.

Still, it was important that in a study dealing with vouchers, where peoples preconceived ideas and prejudices about the subject matter directly affect their approach to the actual research being conducted, I make a concerted effort to alleviate as many concerns as possible in the manner by which the research methodology was administered. Therefore, as transparent an effort as was possible was made at the beginning of the study to make certain that everyone involved understood the purpose of the research as it pertained to the immediate academic improvement of high school students utilizing the EdChoice voucher program. It was by using this approach that I was able to make my first initial contacts with both the Toledo Public School system and the private and parochial schools that where the direct stake-holders in Ohio's EdChoice voucher program.

The Toledo Public School system provided me with the names and pertinent information of those students in their district who had used the EdChoice voucher system, and from that information I was able to create the initial database that sorted out and identified only those students who met the criteria as was set out in my research methodology. This initially proved to be extremely beneficial, as it allowed me to directly locate the voucher student's school of choice. In doing so, it also became possible to begin contacting those schools in order to obtain the permission necessary to access the academic data from the Spring 2007 OGT tests taken by those students.

The OGT test was chosen as an indicator for determining academic improvement for several reasons. The first reason is that it functions as an already known and 
evaluated commodity used for acquiring multiple academic performance indicators for students in a particular year of schooling, assuring that all students tested the first time as sophomores are evaluated on an assumed level of acquired knowledge as it regards the five core subject competencies. Secondly, the test is administered on a statewide basis, ensuring that students are taking the same tests regardless of their location or the type of school that they attend. Also, because the 2006-2007 academic year was the first year the EdChoice voucher plan was offered to Toledo Public School students, I could isolate freshman who were in the Toledo Public School system for the 2005-2006 school year and track those students who left the district their sophomore year due to the use of the EdChoice voucher. Knowing that these voucher students had had the same freshman curriculum and teachers as those students still attending Toledo Public Schools, I could compare the results of the two sets of OGT testing data taken as sophomores, determining if the voucher schools had caused the scores to increase in a significant manner over those students still attending the public schools.

It was in the initial contacts with the parochial and private schools that I received what, at the time, seemed to be positive feedback regarding their cooperation and participation in the study. All aspects and intentions of the study where explained, and the legitimacy of the study was validated for those schools seeking such conformation. The schools, both private and parochial, expressed concerns regarding some of the issues relating to the political implications of a study such as this one, but gave no direct indication that they would not be willing to further participate as it regarded disclosing the OGT scores of those individual students utilizing the EdChoice vouchers. 
Soon after this, however, the tone and direction of my contacts, specifically in the parochial schools, took a decidedly negative turn. I was informed that the OGT scores for the voucher students would no longer be disclosed to me, regardless of the merit, purpose, or authenticity of my research. I was told that this new position was directly related to the political change that had recently taken place in the governorship of the State of Ohio, including the newly elected governors outspoken dislike for the EdChoice voucher program as it was currently being implemented.

The administrator of one parochial school that had initially been prepared to cooperate in my study informed me that any research study showing negative or inconclusive results regarding academic achievement by those voucher students being studied could possibly give lawmakers a justification for ending the entire program. The consequences of such an action, I was told, could lead to the disenfranchisement of an entire group of underprivileged urban students who were accessing one of the few legitimate means of quality education in the city. In the end, I was denied access to any of the student's scores from the parochial schools that enrolled students meeting my research criteria. Eventually, the OGT scores for two qualifying EdChoice voucher students attending private schools were released for my use in the study.

Further compounding my frustration was the evasive and generally uncooperative stance taken on the part of the Ohio Department of Education. On recommendation from multiple sources, I queried several individuals within the Department of Education, looking to obtain the necessary OGT scoring data for the voucher students I was attempting to study. The assumption was that, because the EdChoice voucher system was funded directly through taxpayer monies, the state would have a system in place to 
allow researchers access to data that would be invaluable in determining the effectiveness of a voucher system whose purpose is to improve the academic performance of those students utilizing it. Instead, I was informed that no such data collection mechanism was currently in place due to a lack of funding to implement such a tracking system.

I was later told that while scores were compiled for individual students OGT tests, the information regarding those scores could not be released due to privacy concerns. When I inquired further regarding the FERPA exclusion for cases in which legitimate school related officials could be granted access to student records for the purposes of academic research, my inquiries ceased to be responded too. These types responses regarding my questions about the EdChoice voucher students were a ubiquitous overture among those within the Ohio Department of Education. For reasons currently unknown, the access to, and release of OGT scoring data for these voucher students is nearly impossible to obtain.

The actual outcomes of the two students OGT scores that I was able to obtain were not dramatically improved when compared to their counterparts in the Toledo Public Schools as was indicated in my data analyses. Of course, given the small size of the sample, no strong conclusions could be drawn from that data. But, one might assume that it was highly likely that the lack of cooperation on the part of the parochial schools was evidence of their lack of confidence in how their voucher students OGT scores would compare with those of the Toledo Public Schools students.

I would like to think that if the OGT scores were exceptionally high across the range of participating EdChoice voucher students in the parochial schools, the schools themselves would have been more than happy to offer those scores as a validation of the 
immediate improvements offered by the voucher option. Instead, for reasons unknown to me at this point, they simply refused to engage in what may have been an extremely enlightening opportunity for both the schools and the public at large.

My overriding conclusions at this point are imbued with a deep sense of skepticism. If a highly touted initiative such as Ohio's voucher system creates a complex mechanism that operates with essentially no checks, and its constituents are unwilling to allow themselves to be studied in a manner that is completely within the realm of legitimate academic research, the possible conclusions cannot be much more than pessimistic. Due to the highly charged political rhetoric associated with the entire spectrum of vouchers and their use in the public school systems, it is currently highly unlikely that a modicum of reliable and authentic data can be gathered in sufficient quantities to adequately assess the current Ohio EdChoice voucher initiative.

Because of this, the field of study into an area as important and culturally relevant as vouchers has been diminished in some small, yet significant way. However, I believe that the study I conducted, while not being fully realized, can and will shed some light into the causes and concerns of those who may continue to pursue a course of study into this expanding area of educational research. It is certainly an area of research with abundant opportunities for those who wish to continue to pursue data that may reveal a more detailed picture of the educational significance of these modern amalgams of both social and educational reform. 


\section{RECOMMENDATIONS}

If the voucher debate continues to grow more rancorous, those choosing to study these educational "stipends" may be forced to deal with the more abstract variables found outside of the academic context of test scores and their quantitative results. This may involve significantly more research dealing specifically with the qualitative aspects of students who are utilizing vouchers. I came across very little research during this study that dealt adequately with measurements concerning personal growth of voucher students, or the impacts that the voucher may have on a students relationship with his or her parents and their newfound role in their child's education now that they both are direct stake holders in the process.

My experience to this point on the voucher debate would lead me to give pause to anyone seeking to obtain purely statistical research about vouchers based solely on test data. Particularly when the majority of those scores would need to come from what are currently non-participatory institutions, including both government and parochial schools. This does not mean that the research cannot adequately be accomplished. But, had I chose to pursue obtaining the OGT scores directly from the necessary students, it would have inevitably required tracking down the individual students parent(s) or guardians. While this may not be a daunting task in a suburban or rural school district, the sometimes transient existence of many urban families can require immense time and effort when trying to locate an individual students legal guardians, especially when doing so by ones self. Then, even after locating the guardians, I still may or may not have received permission to use the test data. 
It is taking all of these things into consideration, along with the apparent need for a more thorough qualitative analysis of the workings of vouchers, that I would continue to recommend pursuing research into this field of study. I would choose however, to pursue the research in a way that allows for more direct contact with the data acquired while conducting research. Because of the current difficulty in acquiring testing data for students in voucher programs, it may be necessary to perform the research in a manner that allows for more direct contact with the students participating in any future studies. By doing this, one hopes that a more comprehensive understanding of the current voucher system may begin to emerge, allowing for a more detailed analysis of the data currently available. 


\section{REFERENCES}

Study: Voucher students perform same as public school peers. (2004). Black Issues in Higher Education, 20(24), 8-8

Abernathy, S. F. (2005). School choice and the future of american democracy. Ann Arbor: The University of Michigan Press.

Brighouse, H. (2000). School choice and social justice. Oxford: Oxford University Press

Corwin, R.G., \& Schneider, E. J. (2005). The school choice hoax. Westport, CT: Praeger

Costa, A., Sister, Elseginey, S., Lusco, E., \& Pinney, J. (2003). Vouchers: A School Choice

Dwyer, J. G. (2002) Vouchers within reason : A child-centered approach to education reform. Ithaca: Cornell University Press

Forman, M. (2004). School Vouchers and School Choice. Psychology Press. from http://search.epnet.com/login.aspex?direct=trueAuthType $=$ cookie, ip, url,uid\&d=aph\& $\underline{\text { an }=13936304}$

Forman, M. (2004). School vouchers and school choice. Encounter: education for meaning and social justice, 17, 22-24.

Fusarelli, L. D. (2003). The political dynamics of school choice: Negotiating contested terrain. New York, New York: Palgrave Macmillan

Godwin, K. R., \& Kemerer, F. R. (2002). School choice tradeoffs: Liberty, equity, and diversity. Austin, TX: University of Texas Press.

Hanus, J. F., \& Cooksn, Jr. P. W. (1996). Choosing schools: Vouchers and american education. Washington D.C.: American University Press.

Harmer, D. (1994). School choice: Why you need it-how you get it. Washington D.C.: Cato Institute

Hess, F. M. (2002). Revolution at the margins: The impact of competition on american urban school systems. Washington D.C.: Brookings Institution Press.

Hill, P. T., Campbell, D. E., \& Koret Task Force on K-12 Education. (2002). Choice with equity. Stanford, Calif.: Hoover Institution Press, Stanford University 
Howell, W. G., Wolf, P.J., Campbell, D. E., \& Peterson, P. E. (2002). School vouchers and academic performance: Results from three randomized field trials. Journal of Policy Analysis and Management, 21(2), 191-217.

Howell, W. G., \& Peterson, P. E. (2002). The education gap: Vouchers and urban schools. Washington D.C.: The Brookings Institution Press.

Hoxby, C. M. (Ed.). (2003). The economics of school choice. Chicago \& London: The University of Chicago Press.

Kahlenberg, R. D. (Ed.). (2003). Public school choice vs. private school choice. New York: The Century Foundation Press.

Kirkpatrick, D. W. (1990). Choice in schooling: A case for tuition vouchers. Chicago, IL: Loyola University Press.

Krueger, A.B., \& Pet Zhu, A. B. (2004). Another look at the new york city school voucher experiment. American Behavioral Scientist. 47(5), 658-698. Retrieved June 21,2005 , from the professional development collection database.

McEwan P. J. (2004). The potential impact of vouchers. Peabody Journal of Education, 79(3), 57-80.

McGroarty, D. (1996). Break these chains: The battle for school choice. Rocklin, CA: Prima Publishing.

Merrifield, J. (2002). School choice: true and false. Oakland, CA: The Independent Institute.

Moe, T. M. (Ed.). (1995). Private vouchers. Stanford, CA: Hoover Institution Press.

Moe, T. M. (2001). schools, vouchers, and the american public. Washington D.C.: Brookings Institution Press.

Paul, K., Legan, N., \& Metcalf, K. (2003). A Longitudinal Examination of the Demographic Characteristics of Applicants and Entrants to the Cleveland Scholarship and Tutoring Program

Peterson, P. E. (2003). A choice between public and private schools: What next for school vouchers? Spectrum: The Journal of State Government, Fall, 5-8.

Peterson, P. E., \& Campbell, D. E. (2001). Charters, vouchers, and public education. Washington, D. C.: Brookings Institution Press. 
Peterson, P. E., Howell, W. G. (2004). Efficiency, bias, and classification schemes. American Behavioral Scientist, 47(5), 699-717. Retrieved June 21 2005, from the professional development collection database.

Reyes, A. H., \& Rodriguez, G. M. (2004). School finance. Education \& Urban Society, $37(1), 3-21$.

Sarason, S. B. (2002). Questions you should ask about charter schools and vouchers. Portsmouth, NH: Heinemenn.

Schneider, M., Teske, P., \& Marschall, M. (2000). Choosing schools: Consumer choice and the quality of american schools. Princeton, NJ: Princeton University Press

Sugarman, S. D., \& Kemerer, F. R. (1999). School choice and social controversy: Politics, policy and law. Washinton D.C.: Brookings Institute Press

Walls, C. A., \& ERIC Clearinghouse on Urban Education, New York, NY. [BBB00899]. (2003). A Guide to Voucher Programs for Parents, about Parents

Witte, J. F. (2000). The market approach to education: An analysis of america's first voucher program. Princeton, NJ: Princeton University Press.

Wolfe, A. (Ed.). (2003). School choice: The moral debate. Princeton, NJ: Princeton University Press. 